\title{
Recursos para a aualiação da aprendizagem no ensino superior: possibilidades digitais
}

\author{
Resources for the assessment of learning in higher education: digital \\ possibilities
}

\author{
Recursos para la evaluación del aprendizaje en la enseñanza \\ superior: posibilidades digitales \\ Louise de Quadros da Silva' \\ Universidade La Salle Canoas, Curso de Pedagogia, Secretária da Reitoria. \\ https://orcid.org/0000-0002-8632-3374 \\ Hildegard Susana Jung ${ }^{2}$ \\ Universidade La Salle Canoas, Curso de Pedagogia, Professora. \\ https://orcid.org/0000-0001-5871-3060 \\ Paulo Fossatti ${ }^{3}$ \\ Universidade La Salle, Reitor \\ http://orcid.org/0000-0002-9767-5674
}

Resumo: 0 objetivo da pesquisa consiste em refletir sobre as possibilidades de uso do Google Forms para a avaliação da aprendizagem no ensino superior. Trata-se de uma pesquisa exploratória, com aplicação de um questionário a 189 professores. Os resultados apontam para: 1. A possibilidade de elaboração de atividades remotas por meio do recurso em estudo; 2. Variados tipos de questões; 3. Aplicação da avaliação presencialmente ou online; 4. Feedback instantâneo; 5 . Análise das respostas através de planilhas ou gráficos; 6 . Facilidade em realizar o download ou arquivamento no drive; e 7. Possibilidade de discussão dos resultados com os estudantes através dos relatórios disponiveis. Concluímos que o Google Forms possui diferentes possibilidades para a avaliação no ensino superior, mas salientamos a necessidade de preparo e desenvolvimento por parte dos docentes para trabalhar com essa tecnologia.

Palavras-chave: Avaliação por competências. Google Forms. Prática docente com tecnologias.

Mestre em Educação pela Universidade La Salle Canoas; Graduada em Recursos Humanos pela Universidade La Salle Canoas.

2 Doutora em Educação pela Universidade La Salle Canoas; Mestre em Educação pela Universidade Regional Integrada do Alto Uruguai e das Missões.

3 Pós-doutor em Ciências da Educação pela Universidade do Algarve; Doutor em Educação pela Pontifícia Universidade Católica do Rio Grande do Sul. 
Abstract: The objective of the research is to reflect on the possibilities of Google Forms for the assessment of learning in higher education. This is a exploratory research, with application of a questionnaire to 189 teachers. The results point to: 1. The possibility of developing remote activities through the resource under study; 2. Varied types of question questions; 3. Application of the assessment in person or online; 4. Instant feedback; 5. Analysis of responses through spreadsheets or graphs; 6. Ease of downloading or archiving the drive; and 7. Possibility of discussing the results with students through the available reports. We concluded that Google Forms has different possibilities for evaluation in higher education, but we emphasize the need for preparation and development by teachers to work with this technology.

Keywords: Competency assessment. Google Forms. Teaching practice with technologies.

Resumen: El objetivo de la investigación consiste en reflexionar sobre las posibilidades de Google Forms para la evaluación del aprendizaje en la enseñanza superior. Se trata de una investigación exploratoria, con aplicación de un cuestionario a 189 profesores. Los resultados señalan: 1. La posibilidad de elaboración de actividades remotas por medio del recurso en estudio; 2. Variados tipos de cuestiones; 3. Aplicación de la evaluación presencialmente u online; 4. Feedback instantáneo; 5. Análisis de las respuestas a través de hojas de trabajo o gráficos; 6. Facilidad para realizar el download o guardar en drive; 7. Posibilidad de discusión de los resultados con los estudiantes a través de los informes disponibles. Concluimos que Google Forms posee diferentes posibilidades para la evaluación en la enseñanza superior, pero subrayamos la necesidad de preparación y desarrollo de parte de los docentes para trabajar con esa tecnología.

Palabras clave: Evaluación por competencias. Google Forms. Práctica docente con tecnologías.

Recebido em 30 de julho de 2020

Aceito em 29 de dezembro de 2020

\section{INTRODUÇÃO}

Com os constantes avanços tecnológicos, vivemos em uma realidade na qual a grande maioria da sociedade está imersa em tecnologias digitais conectadas. Neste sentido, Favarin e Rocha (2015, p. 60) afirmam: "Os estudantes do século 21 já nasceram na cultura digital e por isso são reconhecidos como nativos digitais." Sabemos que esta citação se refere apenas a uma parcela da população, pois, existem jovens que não sabem lidar com tecnologias, tanto quanto, pessoas de mais idade que estão conectados diariamente. Em vista disso, a educação precisa se atentar às novas realidades e, mais do que se adaptar à Era tecnológica, é importante que as instituições de ensino visem a inovação a partir da apropriação das tecnologias. 
Considerando as implicações da pandemia causada pela doença COVID-19, vemos que a tecnologia, rapidamente, se tornou ainda mais importante para a educação. Com o distanciamento social, decretado a fim de controlar a propagação desta doença, o ensino passou a ser realizado, principalmente, por meio de tecnologias, síncronas e assíncronas. Neste cenário, os artefatos da Google For Education se tornaram uma das tecnologias mais utilizadas nos últimos meses. Cabe destacar que a Google For Education é uma plataforma com diferentes ferramentas, dentre as quais temos o pacote o Gsuite, que dispõe de um aparato de artefatos para a área educacional.

A plataforma digital, Brasil Escola, por exemplo, apresenta uma matéria intitulada “Criar provas utilizando o Google Forms" (SANTOS, [2020]), na qual afirma que este artefato "[...] é uma forma prática de realizar avaliações online." No mesmo sentido, a empresa Agência de Marketing Educacional (REACT, 2020) destaca que a transformação digital do ensino é necessária, mas tem sido adiada, por não ser considerada urgente. Porém, "De repente, um vírus (COVID-19) nos impede de sair de nossas casas, forçando uma quarentena, impactando profundamente a rotina de vários setores do mercado." (REACT, 2020). Dessa forma, a Agência de Marketing Educacional (REACT, 2020), a fim de auxiliar as instituições de ensino, disponibiliza cinco tutoriais com ferramentas gratuitas, sendo a primeira sobre o seguinte assunto: "Aplicar testes de conhecimento com o Google Forms." (REACT, 2020).

É necessário entender as particularidades dos estudantes de hoje e buscar melhores maneiras de ensinar e avaliar a aprendizagem. Nesse sentido, surge a avaliação por competências que se volta para o desenvolvimento contínuo do educando, com feedbacks e diálogos. Além disso, formar pessoas nesse contexto, exige que o professor instigue e qualifique seus discentes com capacidades e aptidões, não apenas para obter compreender conteúdos, mas para desenvolver competências, saber fazer e pensar de forma autônoma. Dessa maneira, Favarin e Rocha (2015, p. 60) salientam que: "Ensinar essa nova geração é um desafio, especialmente para os professores, pois estes precisam avançar em relação a aula expositiva e deixar que os estudantes aprendam a partir de suas próprias experiências."

A partir dos avanços tecnológicos, apontamos o Google Forms ou também chamado de Google Formulários, como uma possibilidade para auxiliar no processo avaliativo na educação superior. Optamos em pesquisar sobre um artefato da Google e não de outras empresas de soluções tecnológicas, porque percebemos a procura por essas tecnologias por parte de instituições de ensino. Isso possivelmente possa ser justificado porque "[...] a Google liberou diversos recursos de educação para facilitar a vida de quem precisa ensinar sem uma sala de aula." (MOGNON, 2020). No entanto, salientamos que existem outros artefatos que também merecem reconhecimento. Assim, nossa pesquisa tem por objetivo refletir sobre as possibilidades do Google Forms para a avaliação da aprendizagem. Acreditamos que nosso estudo contribuirá para a divulgação e discussão sobre novas maneiras de realizar 
processos avaliativos, ou mesmo, processos em geral dentro das instituições de ensino superior (IES).

Para este artigo, realizamos uma pesquisa empírica e bibliográfica. Nesse sentido, nos embasamos em Lakatos e Marconi (2009) e Bardin (2011), no que se refere aos critérios de seleção dos materiais a serem estudados e para a elaboração das etapas do processo de pesquisa, bem como a organização e escrita. A seguir veremos a estrutura deste trabalho, no qual, após esta breve introdução, descrevemos a metodologia utilizada nesta investigação de forma mais detalhada. 0 referencial teórico está descrito como avaliação da aprendizagem no ensino superior. Por fim, avançamos para a análise e discussão dos dados abordada no item quatro, seguida das considerações finais.

\section{ABORDAGEM METODOLÓĢICA}

Para a compreensão do tema indicado, optamos pela pesquisa bibliográfica, a qual conforme Lakatos e Marconi (2009, p. 43-44): “Trata-se de levantamento de toda a bibliografia já publicada, em forma de livros, revistas, publicações avulsas e imprensa escrita." Nos referimos a este estudo como exploratório, pois visa proporcionar maior familiaridade com o problema, considerando o levantamento bibliográfico e o questionário (GIL, 2008). Segundo Lakatos e Marconi (2009, p. 44), percorremos as seguintes oito fases: “a) escolha do tema; b) elaboração do plano de trabalho; c) identificação; d) localização; e) compilação; f) fichamento; g) análise e interpretação; e h) redação."

Dessa maneira, iniciamos com a escolha do tema a partir de uma avaliação da atualidade e da significância para a sociedade. Feito isso, na elaboração do plano de trabalho organizamos dentro do período de quatro meses as atividades que seriam realizadas para que mantivéssemos um prazo. A partir de nossa pesquisa bibliográfica, efetuamos primeiramente uma leitura flutuante dos títulos e resumos conforme Bardin (2011) para selecionar os trabalhos pertinentes, seguida dos fichamentos da bibliografia mantida.

Além disso, incluímos uma pesquisa empírica com a finalidade de aprofundar nossos achados bibliográficos. Esta etapa da pesquisa foi realizada a partir de um questionário com quatro questões (objetivas e dissertativas) enviadas por meio do Google Forms, para 189 professores de uma universidade comunitária da região metropolitana de Porto Alegre, dos quais 44 responderam. Tais questões tiveram como foco verificar a percepção e o conhecimento dos docentes da instituição pesquisada referente ao uso do Google Formulários em avaliações. Dessa forma, o número de respondentes corresponde a 23,28\% dos docentes da instituição. 0 questionário teve caráter anônimo, sem nenhum contato direto com os 
respondentes, sendo enviado no mês de outubro, com dois reforços no mesmo mês. Este tipo de pesquisa trata-se de um método, que segundo Gil (2008, p. 121) é composto "[...] por um conjunto de questões que são submetidas a pessoas com o propósito de obter informações sobre conhecimentos, crenças, sentimentos, valores, interesses, expectativas, aspirações, temores, comportamento presente ou passado etc."

No que se refere à fase de análise e interpretação dos dados, nos embasamos na análise de conteúdo de Bardin (2011, p. 47) que, conforme a autora, trata-se de "[...] um conjunto de técnicas de análise das comunicações visando a obter, por procedimentos sistemáticos e objetivos de descrição do conteúdo das mensagens, indicadores (quantitativos ou não) que permitam a inferência de conhecimentos." Por fim, redigimos o texto, momento este em que através da triangulação dos dados, discutimos o tema entre o referencial teórico, os achados da pesquisa e a interferência dos pesquisadores.

\section{AUALIAÇÃO DA APRENDIZAGEM NA EDUCAÇÃO SUPERIOR}

Iniciamos este tópico pela compreensão do termo avaliação quando referido à educação. Segundo Libâneo (2013, p. 209) refere-se à verificação e controle do rendimento escolar, tendo "[...] uma função didática que percorre todas as etapas do ensino, e abrange a consideração dos vários tipos de atividades do professor e dos alunos no processo de ensino." Nesse sentido, salientamos que este processo precisa ser bem elaborado para que não se torne uma ferramenta de punição, mas sim um meio pelo qual seja possível verificar o desenvolvimento do estudante e entender as dificuldades do mesmo, bem como as principais limitações e aptidões. Isso porque a "[...] avaliação pode gerar transformações, justificativas ou descrédito sobre o que se avalia, dependendo dos múltiplos fatores que a influenciam." (MARINHO-ARAUJO; RABEL0, 2015, p. 444).

Compreendemos que "[...] é imprescindivel considerar, no planejamento e na elaboração de instrumentos avaliativos, formas de se 'capturar' a complexidade de significados e sentidos presentes nos aspectos subjetivos e intersubjetivos dos processos educativos." (MARINHO-ARAUJO; RABELO, 2015, p. 444). Daí a importância de entendermos o contexto de cada estudante e sabermos avaliar nossos educandos, não apenas por uma atividade isolada, mas como um todo. Como já referido anteriormente, Luckesi (2000, p. 1) ressalta que a avaliação não deve ser vista como um ato de punição, pois "[...] não é e não pode continuar sendo a tirana da prática educativa, que ameaça e submete a todos." Ou seja, esta deve ser "[...] amorosa, inclusiva, dinâmica e construtiva, diversa dos exames, que não são amorosos, são excludentes, não são construtivos, mas classificatórios." (LUCKESI, 2000, p. 1). 
Complementando, Libâneo (2013, p. 209) diz que a avaliação precisa ser vista como um acompanhamento do processo de ensino-aprendizagem, "[...] um processo sistemático e contínuo, [...] a partir de parâmetros de desempenho escolar." Nesse sentido, vemos que existem variados meios e procedimentos de apoio à verificação dos objetivos atingidos, ou seja, de avaliação do conteúdo compreendido pelo estudante. Assim, apresentamos alguns exemplos: atividades, testes, provas, exercícios práticos e teóricos, tarefas, trabalhos individuais ou em grupo, além da observação e autoavaliação.

Agora que percebemos que existem diferentes maneiras de realizamos avaliações da aprendizagem, reafirmamos a relevância de pensarmos em formas de usar as tecnologias digitais, também, neste viés. Portanto, a fim de atender nosso objetivo de pesquisa que consiste em refletir sobre as possibilidades do Google Forms para a avaliação no ensino superior, entendemos ser relevante discutirmos sobre o processo de aprendizagem. $\mathrm{Na}$ sequência, dividimos nosso referencial teórico em três principais tópicos, a saber: Processo de aprendizagem; Abordagem por competências; e Avaliação por competências no ensino superior (Diagnóstica; Formativa; e Somativa).

\subsection{PROCESSO DE APRENDIZAGEM}

A aprendizagem se dá pela aquisição de novos conhecimentos, habilidades, competências, etc. Assim como descrevem Zeferino e Passeri (2007, p. 39): “0 processo de aprendizagem pode ser definido de forma sintética como o modo como os seres humanos adquirem novos conhecimentos, desenvolvem competências e mudam o comportamento." $\mathrm{Na}$ mesma perspectiva, Lefrançois (2008, p. 5) acrescenta: "[...] a aprendizagem é definida como toda mudança relativamente permanente, de comportamento, que resulta da experiência."

Considerando as constantes mudanças sociais, entendemos que esta aprendizagem, de que falamos, precisa ser significativa para o estudante, ou seja, deve prepará-lo para situações e problemas reais (ALMEIDA, 2018, p. 9). Segundo Gomes (2018, p. 135), no início do século XX um dos princípios pedagógicos da educação era o "[...] integral, por meio do vínculo entre atividades manuais e intelectuais, que possibilitasse o desenvolvimento progressivo e equilibrado do ser humano." Complementando, entendemos que a "[...] aprendizagem deve estar voltada para a formação ampla do profissional e não se limitar apenas ao aspecto cognitivo da aprendizagem." (ZEFERINO; PASSERI, 2007, p. 40). Desse modo, a educação precisa desenvolver estudantes de forma plena, capacitando-os para as diversas situações da vida. 
Em vista disso, Zeferino e Passeri (2007, p. 39) consideram "[...] que a aprendizagem efetiva envolve três domínios básicos: cognitivo, psicomotor e afetivo, que, de forma integrada, podem ser denominados competências na aprendizagem". Nesse contexto, o docente precisa ser capaz de utilizar seus conhecimentos e habilidades para mediar "[...] construções de aprendizagem, e mediar é intervir para promover mudanças." (ZEFERINO; PASSERI, 2007, p. 39). Neste contexto, a aprendizagem integral está diretamente relacionada com a prática docente reflexiva, pois é o educador quem deve preparar atividades que possibilitem tal desenvolvimento (ALMEIDA, 2018).

\subsection{ABORDAGEM POR COMPETÊNCIAS}

A partir dos materiais apresentados até então, compreendemos que o processo de aprendizagem é amplo e deve ser fomentado de forma integral no estudante, o que nos implica pensar na aprendizagem por competências. Estas, por sua vez, são percebidas por Fleury e Fleury (2001, p. 185) "[...] como estoque de recursos, que o indivíduo detém." Do mesmo modo, Zarifian (1999) e Goergen (2019) descrevem competência como a inteligência prática em situações em que o estudante utiliza os conhecimentos adquiridos para solucionar questões diversas.

Sobre o tema, Fleury e Fleury (2001, p. 185) relatam que "[...] o conceito de competência é pensado como conjunto de conhecimentos, habilidades e atitudes listo é, conjunto de capacidades humanas) que justificam um alto desempenho." Competência também pode ser considerada, conforme Silva e Ramos (2018), como a capacidade de cumprir determinada tarefa, empregando conjuntamente conhecimentos e saberes. Semelhantemente, a entendemos como "[...] o conjunto de aprendizagens sociais e comunicacionais nutridas a montante pela aprendizagem e formação e a jusante pelo sistema de avaliações." (FLEURY; FLEURY, 2001, p. 187). De modo que competência se refere a “[...] um saber agir responsável e reconhecido, que implica mobilizar, integrar, transferir conhecimentos, recursos e habilidades, que agreguem valor econômico à organização e valor social ao indivíduo." (FLEURY; FLEURY, 2001, p. 187, grifo do autor).

Percebemos que o desenvolvimento social implica em mudanças na educação e, por conseguinte, na avaliação da aprendizagem. A sociedade necessita de pessoas preparadas para as diversidades que o mundo dispõe e por isso as instituições educacionais devem se atentar cada vez mais ao desenvolvimento de seus estudantes, e associar à aprendizagem de conteúdos cognitivos, e competências variadas. Lembrando que, historicamente, aos poucos "[...] o termo competência foi sendo associado a uma variedade de atributos como 
capacidades, aptidões, qualificações, que seriam adequados e esperados à execução de determinadas atividades profissionais." (MARINHO-ARAUJO; RABELO, 2015, p. 449).

Desse modo, verificamos que ser competente em uma atividade ou prática significa ser capaz de utilizar conhecimentos relevantes para abordar certas situações e problemas relacionados a essa área (COLL, 2007). No mesmo sentido, Fleury e Fleury (2001, p. 189) trazem que: "Competência seria assim a capacidade de combinar, misturar e integrar recursos em produtos e serviços." Por isso, "[...] a necessária integração de diferentes tipos de conhecimento (habilidades práticas e cognitivas, conhecimento factual e conceitual, motivação, valores, atitudes, emoções, etc.) é outro aspecto essencial das abordagens baseadas em competências." (COLL, 2007, p. 36, tradução nossa).

Consequentemente, notamos que a competência de um indivíduo se dá pela capacidade deste em articular seus conhecimentos a suas habilidades para determinadas ações. De modo que Marinho-Araujo e Rabelo (2015, p. 451) indicam: “Aprender a identificar, mobilizar, gerenciar e utilizar esses conjuntos de recursos, articulados a habilidades, saberes, conhecimentos e outras características pertinentes, é o que oportuniza a visibilidade de uma competência."

\subsection{AUALIAÇÃO POR COMPETÊNCIAS NO ENSINO SUPERIOR}

Em uma sociedade contemporânea que avança constantemente, a educação sofre mudanças no que se refere a currículos, ambientes físicos, materiais didáticos, metodologias, estratégias de ensino, entre outros. Isso tudo para proporcionar meios de desenvolver estudantes (futuros profissionais) autônomos, criativos, críticos e empreendedores. Assim, percebe-se que não basta ao discente aprender, é necessário saber fazer, pois "[...] fazer requer do estudante a habilidade de colocar em prática seu conhecimento, saber aplicar esse conhecimento à realidade da profissão." (ZEFERINO; PASSERI, 2007, p. 39).

Neste cenário de mudanças, como avaliar? 0 processo de avaliação não deve mais ser visto como algo árduo, rígido e negativo, mas sim como um processo constante de desenvolvimento. 0 docente tem de estar sensivel às particularidades de cada estudante, pois ele deve "[...] antes de mais nada, acolhê-lo no seu ser e no seu modo de ser, como está, para, a partir daí, decidir o que fazer", se opondo a ações de exclusão, tornando o processo mais amoroso e acolhedor (LUCKESI, 2000, p. 2).

0 mesmo autor ainda sintetiza o processo avaliativo como "[...] um ato pelo qual, através de uma disposição acolhedora, qualificamos alguma coisa (um objeto, ação ou pessoa), tendo em vista, de alguma forma, tomar uma decisão sobre ela." (LUCKESI, 2000, p. 4). 
Destacamos também, a importância de se ater aos pequenos detalhes, pois o docente precisa estar "[...] disponível para acolher nossos educandos no estado em que estejam, para, a partir daí, poder auxiliá-los em sua trajetória de vida." (LUCKESI, 2000, p. 10).

Nesse sentido, a avaliação precisa ser mais compreensiva, integrando o contexto e a compreensão do discente como um todo. 0 processo avaliativo precisa desempenhar o papel de acompanhar e buscar meios para sanar dificuldades e desenvolver o estudante. Hoffmann (1994, p. 57) diz que essa forma de avaliar possui um processo de construção do conhecimento que "[...] implica favorecer o desenvolvimento do aluno, orientá-lo nas tarefas, oferecer-lhe novas leituras ou explicações, sugerir-lhe investigações, proporcionar-lhe vivências enriquecedoras e favorecedoras à sua ampliação do saber." Complementando, Luckesi (2000, p. 1) afirma:

Chega de confundir avaliação da aprendizagem com exames. A avaliação da aprendizagem, por ser avaliação, é amorosa, inclusiva, dinâmica e construtiva, diversa dos exames, que não são amorosos, são excludentes, não são construtivos, mas classificatórios. A avaliação inclui, traz para dentro; os exames selecionam, excluem, marginalizam.

Dessa maneira, torna-se vital para a educação pensar em novas formas de realizar avaliações, pois como dizem Zeferino e Passeri (2007, p. 40): “Estamos numa época em que a avaliação da aprendizagem já não é mais compreendida como o ato de medir o desempenho de um estudante. A avaliação é um instrumento de aprendizagem, pois exerce um poderoso efeito sobre ela." Os mesmos autores ainda agregam dizendo que o processo de avaliação tem como principal objetivo medir o alcance dos objetivos propostos.

Avaliação, principalmente, quando referida às competências do estudante requer uma relação dialógica, em que docentes e discentes, em um processo cíclico constroem processos de aprendizagem. Este, por sua vez, concebe "[...] o conhecimento como apropriação do saber pelo aluno e também pelo professor, como ação-reflexão-ação que se passa na sala de aula em direção a um saber aprimorado, enriquecido, carregado de significados, de compreensão." (HOFFMANN, 1994, p. 56).

Zeferino e Passeri (2007) acreditam que a avaliação deve ser aquela que observa as competências obtidas durante certo período de tempo, e para isso são usados meios quantitativos e qualitativos de análise do comportamento humano. No mesmo sentido, os autores Marinho-Araujo e Rabelo (2015, p. 460) consideram entre os eixos desta avaliação, "[...] diversos indicadores: conhecimentos, saberes, habilidades, posturas, escolhas e demais recursos a serem mobilizados pelos sujeitos mediados pelo processo de formação, pelo contexto e pela natureza das tarefas." 
Para uma avaliação por competências de qualidade, compreendemos com base em Zeferino e Passeri (2007), e Klein e Scarpatto (2017) a importância das três fases fundamentais, a saber: Avaliação Diagnóstica; Avaliação Formativa; e Avaliação Somativa. E por isso, veremos a seguir o conceito de cada uma dessas.

Avaliação diagnóstica acontece durante o processo educativo, principalmente antes de se iniciar um novo assunto, com intuito de diagnosticar, verificar e apontar pontos fracos e fortes de cada estudante em determinada área de conhecimento. Para que se possa avançar nos conteúdos é extremamente importante ter ciência dos saberes prévios do discente. Esta tipologia de avaliação busca compreender o nível de aprendizagem da turma para que o professor possa elaborar suas atividades de maneira mais assertiva. No mesmo sentido, vemos que esta "[...] tem como propósito constatar se os alunos possuem os conhecimentos básicos e imprescindiveis às novas aprendizagens." (ZEFERINO; PASSERI, 2007, p. 40). Klein e Scarpatto (2017, p. 20) complementam dizendo que tal avaliação "[...] é a mais importante na prática escolar, pois ocorre no início, durante e no final do desenvolvimento das aulas, permitindo identificar o progresso e as dificuldades dos alunos e a atuação do professor para que se possa cumprir os objetivos."

A avaliação formativa, por sua vez, é realizada de forma contínua durante o desenvolvimento de conhecimentos com os estudantes, a fim de verificar os avanços e entraves de cada discente para assim ajustar os meios de ensino. Ou seja, a "[...] avaliação formativa é aquela realizada no decorrer do curso com o objetivo de verificar se os alunos estão dominando gradativamente cada etapa proposta." (ZEFERINO; PASSERI, 2007, p. 40). Muitas são as possibilidades de instrumentos que podem ser utilizados na avaliação deste tipo, e o professor é quem deve estar atento às particularidades de seus estudantes para adequar as técnicas. Alguns exemplos são: a prova escrita com questões dissertativas, prova oral, portfólio, auto avaliação do estudante, entre outros (ZEFERINO; PASSERI, 2007). A Avaliação Formativa tem função de controle, e "[...] possibilita o diagnóstico das situações didáticas, através da frequência das verificações e da qualificação dos resultados escolares." (KLEIN; SCARPATTO, 2017, p. 20). De tal modo que essas verificações são consideradas pelos mesmos autores como "[...] um controle sistemático e contínuo, ocorrendo no processo de interação do professor com o aluno em aula, atividades em grupo, entre outras." (KLEIN; SCARPATTO, 2017, p. 20).

Já a avaliação somativa, que ocorre ao fim do curso, aula ou conteúdo, tem como função averiguar se o estudante atingiu os objetivos propostos. Esta possui também um caráter de retorno ao estudante, mas difere-se das anteriores por conter obrigatoriamente a atribuição de notas, conceitos, ou ainda de um parecer descritivo, promovendo o estudante a um nível subsequente ou não. Concordando, Zeferino e Passeri (2007, p. 42) conceituam a avaliação somativa como aquela "[...] que consiste em identificar se o estudante adquiriu as 
competências necessárias para desenvolver novas etapas do processo de aprendizagem." Também conhecida como pedagógico-didática por Klein e Scarpatto (2017, p. 20), que diz que esta avaliação consiste em verificar o "[...] cumprimento dos objetivos, tanto gerais quanto específicos da educação escolar, possibilitando o aprimoramento e a ampliação do conhecimento e habilidades." Lembrando que esta possui diversos meios de ser realizada, igualmente como descrevemos na avaliação formativa.

Em síntese, podemos dizer que a avaliação por competências deve conter em seu interior os três eixos aqui apresentados para que possa manter um processo contínuo de retroalimentação. Nesta perspectiva, a avaliação “[...] deve ser construída com a participação do estudante para que haja maior envolvimento e aceitação do processo, criando a cultura de que a avaliação é um instrumento de aprendizagem fundamental para o crescimento pessoal e profissional do indivíduo." (KLEIN; SCARPATTO, 2007, p. 43).

\section{O RECURSO GOOGLE FORMS NA AUALIAÇÃO POR COMPETÊNCIAS NO ENSINO SUPERIOR}

Novas tecnologias vêm surgindo constantemente, trazendo mudanças para a sociedade e, consequentemente, para a educação (HABOWSKI; CONTE; TREVISAN, 2019; MARTINS; MASCHI0, 2014). Segundo Rocha e Nogueira (2019, p. 15) “[...] a cooperação (professor $x$ alunos) em ambientes mediados tecnologicamente só tem a contribuir no processo de ensino e aprendizagem dos alunos." Se bem apropriados pelos docentes, esses artefatos podem tornar as aulas mais interessantes e atrativas. Por isso, a formação docente continuada se torna tão importante (ROCHA; NOGUEIRA, 2019), ainda mais, aquelas que consideram as tecnologias (HABOWSKI; CONTE; TREVISAN, 2019).

Nesse sentido, Ferreira e Maraschin (2019, p. 24) afirmam que "Investir em infraestrutura e disponibilizar a tecnologia digital para uso no ensino presencial na universidade, sem investir em um processo formativo inventivo e coletivo dos professores não resultará em mudanças significativas no ensino." Martins e Maschio (2014, p. 13) afirmam que a inserção de tecnologias na educação "[...] deve contribuir para a mudança da prática pedagógica."

No entanto, segundo Quadros da Silva (2019, p. 64) questões que podem dificultar a utilização de tecnologias em sala de aula "[...] é a falta de acesso a elas por parte da população ou mesmo desinteresse e falta de conhecimento." Além da falta de conhecimento ou interesse, temos o possível desconforto que as mudanças organizacionais podem causar nos docentes (VEGRO et al., 2016). 
0 Google Forms é um dos aplicativos disponibilizados de forma online pela Google For Education, que "...] é composta por um pacote de ferramentas que se mostram como uma das mais inovadoras e disruptivas em termos de tecnologia educacional em dimensões globais." (QUADROS DA SILVA; FOSSATTI; JUNG, 2018, p. 15). Este artefato tecnológico facilita processos educacionais como pesquisas e atividades, dentro ou fora da sala de aula. Também é possível utilizá-lo para avaliações diagnósticas, formativas e somativas. Segundo Paul (2016) - Google Forms facilita a criação de questionários, automatizando o processo de design e disponibilizando vários estilos de perguntas, além disso, é bem versátil.

Compreendemos que este aplicativo pode agilizar o processo avaliativo pois, entre as suas funcionalidades, possui a opção de autocorreção para questionários objetivos. Além disso, proporciona uma economia pois não utiliza impressão devido a ser online. Dentre as facilidades que este artefato disponibiliza, podemos descrever conforme o site: a) Obtenção de respostas de forma rápida; b) Diversos temas disponíveis para customizar seu formulário; c) Várias opções de questionário como múltipla escolha, escala linear, entre outros, além da possível adição de vídeos ou imagens; d) Adaptável a diferentes dispositivos como a tela do computador ou do smartphone; e) Respostas são arquivadas automaticamente e podem ser baixadas em formato de planilha ou gráficos; e f) É possível incluir colaboradores para criação, edição ou análise de respostas dos questionários (CRIAR..., 2018).

Entendemos que as três fases de avaliação por competências - Diagnóstica; Formativa; e Somativa - possuem uma importante relação sequencial de desenvolvimento. Isso porque, na primeira fase há o momento de verificação do conhecimento que o estudante já possui. Após, temos o espaço para formação do educando a partir de avaliações que buscam a lapidação e o avanço de novos conteúdos. Por fim, a terceira fase apresenta o resultado das ações realizadas anteriormente, com objetivo de mensurar o alcance dos objetivos propostos.

Nesse sentido, notamos que o Google Forms pode ser utilizado nas três fases, sendo que para a avaliação diagnóstica indicamos não liberar a opção de reenvio do formulário, nem utilizar de pontuação, mas manter todas as questões como obrigatórias. Já para a avaliação formativa observamos a importância de constar o feedback instantâneo e a possibilidade de reenvio para que os estudantes possam repensar sobre suas respostas e compreender, junto ao diálogo com o docente e com a turma, seus erros e acertos. E, na última fase, sugerimos o uso de pontuação e a ativação do modo bloqueado em Chromebooks. Além disso, ressaltamos a importância da revisitação dos resultados após cada atividade, a fim de que as avaliações sejam contribuidoras para a construção do conhecimento.

A avaliação por competências, conforme vimos anteriormente, preza pelo diálogo e o constante feedback para possibilitar que cada atividade possa auxiliar no desenvolvimento do estudante e não ser meramente um exame para a determinação de notas. Portanto, 
verificamos, conforme figura 1, o ciclo da avaliação por competências e ao seu entorno os benefícios da utilização dos Google Forms neste sentido.

Figura 1 - Ciclo da avaliação por competências e os Google Forms

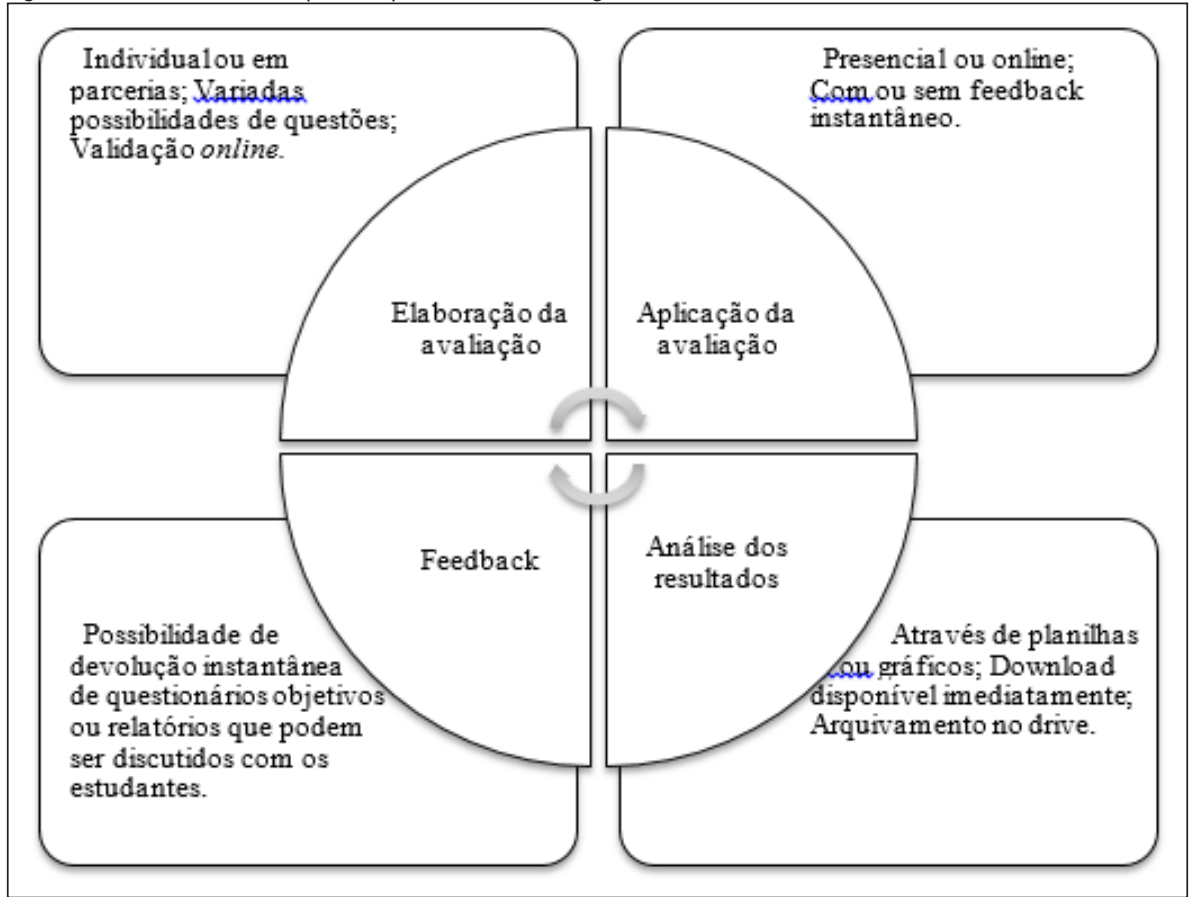

Fonte: os autores.

Deste modo, apontamos, conforme propomos em nosso objetivo, os principais benefícios do uso do Google Forms na avaliação por competências, conforme cada uma dessas quatro etapas: 1) Elaboração da avaliação: várias opções de questionário como múltipla escolha, escala linear, entre outros, além da possível adição de vídeos ou imagens, inclusão de colaboradores para criação, edição ou análise de respostas dos questionários, elaboração de atividades online de forma individual ou em parcerias, diversos temas disponíveis para customizar seu formulário; 2) Aplicação da avaliação: adaptável a diferentes dispositivos como a tela do computador ou do smartphone, avaliação presencialmente ou online; 3) Análise dos resultados: obtenção de resultados de forma rápida, planilhas e gráficos gerados automaticamente, respostas arquivadas automaticamente, facilidade em realizar o download ou arquivamento no drive, acesso de qualquer dispositivo conectado à Internet; 4) Feedback: Feedback instantâneo, material para discussão com os estudantes. 


\subsection{PERSPECTIUA DOS DOCENTES DE UMA UNIUERSIDADE COMUNITÁRIA DA REGIÃO METROPOLITANA DE PORTO ALEGRE SOBRE O GOOGLE FORMS}

Tendo por objetivo refletir a respeito da utilização do Google Formulários para a avaliação no ensino superior, trazemos aqui os resultados empíricos de nosso estudo. Para este, utilizamos de um questionário enviado para 189 professores de uma universidade comunitária da região metropolitana de Porto Alegre, dos quais 23,28\% (44) responderam. As questões foram divididas em três seções: a primeira destinada à obtenção de informações de identificação do universo respondente. Já na segunda seção as questões focaram na verificação de quantos docentes já usavam alguma tecnologias em suas avaliações e, quantos destes utilizavam, especificamente, o Google Formulários, por meios das duas questões como mostramos na sequência: Você utiliza algum artefato tecnológico para a elaboração e/ou correção de provas e trabalhos?; Você utiliza o Google Forms para avaliações?

Por fim, a terceira seção dependia da resposta da segunda pois, para aqueles que responderam não utilizar o Google Formulários, foi questionado sobre seu interesse sobre o mesmo. No entanto, para aqueles que responderam já utilizá-lo, foi solicitado que assinalassem as possibilidades das quais concordavam sobre o Google Forms para avaliações. Dentre as opções a serem assinaladas indicamos todas aquelas obtidas por meio de nossa pesquisa bibliográfica e deixamos a opção para incluir novos elementos.

Para compreendermos o universo de docentes, a primeira sessão de perguntas buscou dados pessoais, tais como faixa etária e o tempo de docência. A partir desses dados, verificamos que a maioria dos respondentes têm de 41 à 50 anos de idade, seguido dos educadores com faixa etária entre 31 e 40 anos, e 51 e 60 anos. Em seus estudos Favarin e Rocha (2015) relembram que as tecnologias podem ser um desafio para docentes que nasceram e se formaram em uma Era diferente, em que não haviam tantos artefatos. Mas, acreditamos que não é a idade que define o nível de apropriação das tecnologias pelos docentes e, neste sentido que nossa pesquisa busca refletir sobre as possibilidades do Google Forms para a avaliação no ensino superior. 
Gráfico 1 - Faixa etária dos respondentes

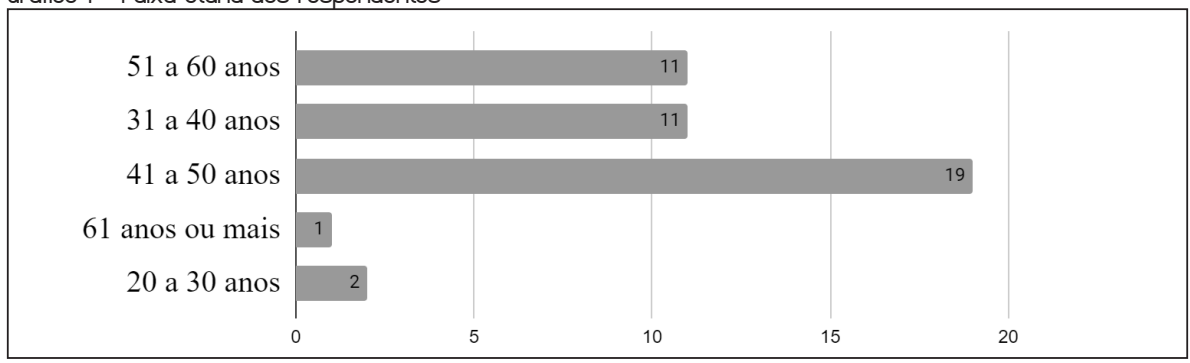

Fonte: os autores.

Já no que se refere ao tempo de docência, vemos que a maioria dos educadores que responderam ao nosso questionário possui mais de 10 anos na área. Esta informação nos indica que, em maioria, as respostas vêm de profissionais experientes da educação. Mas, por outro lado, como nosso tema trata-se de algo, razoavelmente novo, estes docentes podem apresentar resistência sobre o assunto por não terem tido contato com o Google Forms ainda em sua formação inicial. A partir desta informação, percebemos que a maioria dos respondentes possui bastante tempo de experiência, o que nos faz refletir sobre duas possibilidades, estes educadores aprenderam sobre tecnologias a partir de suas experiências ao longo da vida, ou eles foram relutantes para mudar suas tradicionais metodologias de ensino (LEFRANÇOIS, 2008; ZEFERINO; PASSERI, 2007; FAVARIN; ROCHA, 2015).

Gráfico 2 - Tempo de docência

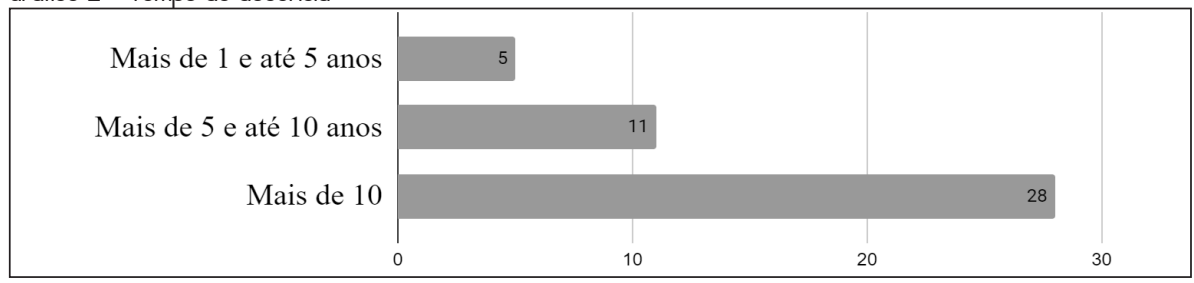

Fonte: os autores.

Ao seguir para a segunda seção do questionário, a qual tratou do tema em si, apresentamos a seguinte questão inicial: Você utiliza algum artefato tecnológico para a elaboração e/ou correção de provas e trabalhos? Desta, 38 docentes afirmaram utilizar algum tipo de artefato tecnológico para este fim, conforme vemos no gráfico a seguir. Este dado nos reafirma que não é a idade que torna um professor desconhecedor das tecnologias, o que nos indica que, possivelmente, seja a falta de interesse conforme indicado por Quadros da Silva (2019) ou o desconforto trazido pelas mudanças, de acordo com Vegro et al. (2016). 
Gráfico 3 - Porcentagem de docentes que utilizam algum artefato tecnológico para a elaboração e/ou correção de provas e trabalhos

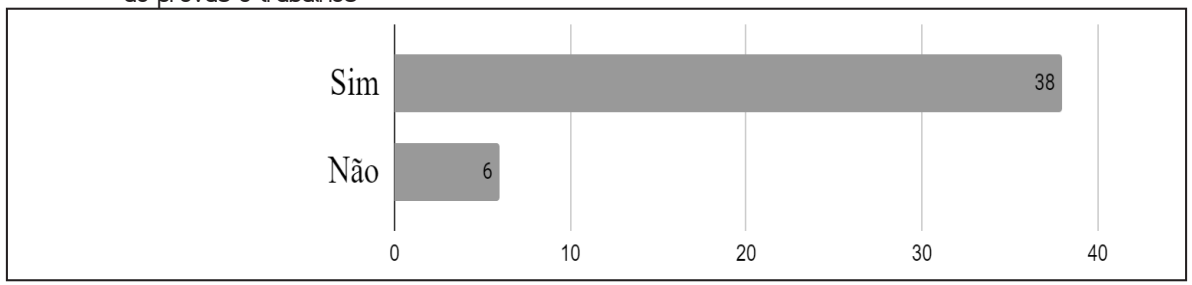

Fonte: os autores.

Na sequência, ao serem questionados sobre utilizarem o Google Forms para avaliações, a maioria, 23 docentes, informou não usar este artefato tecnológico. 0 que nos indica que, apesar de 38 docentes utilizarem tecnologias para suas avaliações, apenas 23 destes incluem o Google Forms no seu dia a dia. Dessa forma, notamos que nossos achados empíricos corroboram com nossos dados bibliográficos, pois, segundo Favarin e Rocha (2015, p. 61) "[...] surge a necessidade de uma formação pedagógica com a integração das tecnologias digitais [...]" Consideramos importante a formação contemplando o uso de tecnologias, não apenas inicial, mas continuada, pois, tecnologias com novas possibilidades de uso na educação, surgem frequentemente (ROCHA; NOGUEIRA, 2019).

Gráfico 4 - Porcentagem de docentes que utilizam o Google Forms

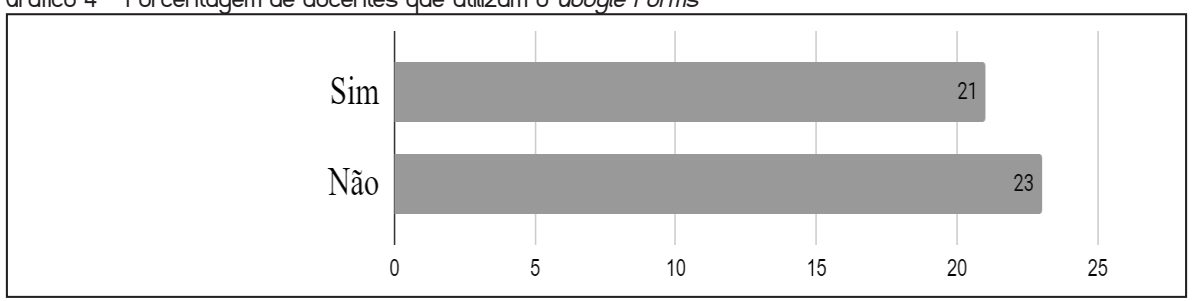

Fonte: os autores.

Neste momento, os docentes que responderam não utilizar o Google Forms em suas avaliações, foram direcionados para a questão: Gostaria de conhecer o Google Forms? Assim, foi possível verificar que, apesar da maioria não utilizar este artefato, 73,9\% destes, o que corresponde à 17 respondentes, são positivos à ideia de conhecê-lo. E, apenas seis não se interessam. Dessa forma, alguns questionamentos surgem sobre os motivos do não uso deste artefato para avaliações, assim como proposto por alguns autores de nosso estudo (VEGRO et al., 2016; FAVARIN; ROCHA, 2015; QUADROS DA SILVA, 2019). Dentre as questões, 
destacamos: 0 não uso de artefatos tecnológicos na avaliação do ensino superior se dá pela falta de formação, interesse ou resistência docente?

Gráfico 5 - Docentes que gostariam de conhecer o Google Forms

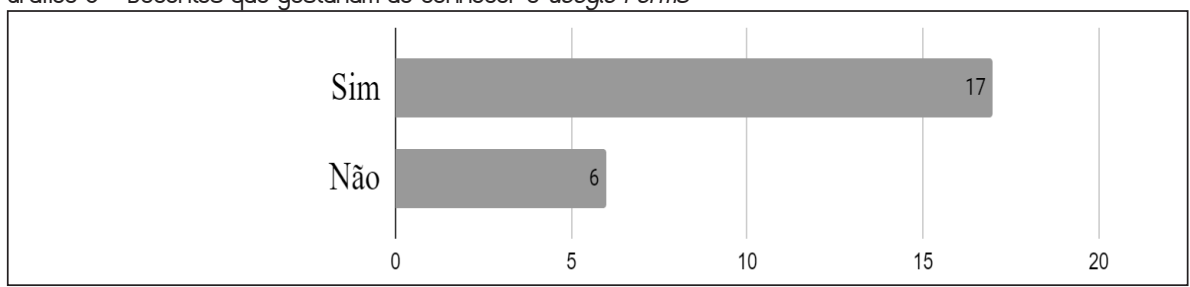

Fonte: os autores.

No entanto, para aqueles que indicaram utilizar o Google Forms em suas avaliações, thes foi apresentada outra questão, a qual solicitou que assinalaram as possibilidades das quais concordavam sobre o Google Forms para avaliações. A partir dos variados itens assinalados, percebemos que nossos dados corroboram com Ferreira e Maraschin (2019) ao afirmarem que é preciso investir não apenas em tecnologias, mas também em formação adequada para os docentes, a fim de que estes se apropriem de tais artefatos e possam torná-los úteis e benéficos para a educação. Vemos a seguir as mais indicadas:

Tabela 1 - Possibilidades do Google Forms para avaliações

\begin{tabular}{lc}
\hline \multicolumn{1}{c}{ Possibilidades do Google Forms para avaliações } & $N^{\circ}$ de menções \\
\hline Várias opções de questionário como múltipla escolha, escala linear, entre outros, além da & 19 \\
possível adição de vídeos ou imagens & 18 \\
Obtenção de respostas de forma rápida & 17 \\
Análise das respostas através de planilhas ou gráficos gerados automaticamente & 16 \\
Adaptável a diferentes dispositivos como a tela do computador ou do smartphone & 16 \\
Respostas são arquivadas automaticamente e podem ser baixadas em formato de planilha & 15 \\
ou gráficos & 15 \\
Aplicação da avaliação presencialmente ou online & 13 \\
Feedback instantâneo & 13 \\
É possível incluir colaboradores para criação, edição ou análise de respostas dos questio- & 12 \\
nários & 1 \\
Elaboração de atividades online de forma individual ou em parcerias & 1 \\
Diversos temas disponíveis para customizar seu formulário & \\
Facilidade em realizar o download ou arquivamento no drive, acesso online e discussão com \\
estudantes
\end{tabular}


A partir desta última pergunta, compreendemos que há diversas possibilidades de uso deste artefato para avaliações no ensino superior, reafirmando que tecnologias podem e devem ser utilizadas na educação, como disposto em nosso referencial teórico (QUADROS DA SILVA; FOSSATTI; JUNG, 2018; FAVARIN; ROCHA, 2015). Entendemos que a maioria, dos docentes que utilizam o Google Forms em suas avaliações (90,5\%), acredita que este é um recurso que possui várias opções de questionário como múltipla escolha, escala linear, entre outros, além da possível adição de vídeos ou imagens.

Das demais respostas, temos por ordem de maior indicação, as seguintes possibilidades: Obtenção de respostas de forma rápida (85,7\%); Análise das respostas através de planilhas ou gráficos gerados automaticamente (81\%); Adaptável a diferentes dispositivos como a tela do computador ou do smartphone, bem como Respostas são arquivadas automaticamente e podem ser baixadas em formato de planilha ou gráficos (76,2\%); Aplicação da avaliação presencialmente ou online, e Feedback instantâneo (71,4\%); Facilidade em realizar o download ou arquivamento no drive, acesso de qualquer dispositivo conectado à Internet, e discussão dos resultados com estudantes (66,7\%); É possível incluir colaboradores para criação, edição ou análise de respostas dos questionários, e Elaboração de atividades online de forma individual ou em parcerias (61,9\%); Diversos temas disponiveis para customizar seu formulário (57,1\%); e Não concordo com nenhuma das opções $(4,8 \%)$.

Analisando as respostas, individualmente, percebemos que todos os docentes assinalaram mais de uma possibilidade dentro do Google Forms para avaliações, com exceção de um, que indicou não concordar com as alternativas listadas. Assim, do total de 44 respondentes, apenas seis docentes não gostariam de conhecer este artefato, o que indica que em maioria os docentes se interessam e acreditam que utilizar o Google Forms para avaliações é uma forma de agilizar processos como quantificar, passar dados para planilhas ou gráficos, entre outras tarefas burocráticas. 0s dados da pesquisa também indicam que a referida tecnologia auxilia os docentes na conferência de resultados e na discussão destes com seus alunos, além de possibilitar feedbacks instantâneos. Dessa forma, a mobilização de conhecimentos, habilidades e atitudes se vê contemplada com a utilização da avaliação por meio de recursos digitais, posto que incentiva a autonomia do estudante, a reflexão e inclusive o trabalho colaborativo, quando for o caso, sem a necessidade da presencialidade, uma vez que podem ser realizadas atividades que respeitem o espaço-tempo de cada um. 


\section{CONSIDERAÇÕES FINAIS}

Em referência ao nosso objetivo que consistia em refletir sobre as possibilidades do Google Forms para a avaliação no ensino superior, vemos que tal aplicativo possui diversas possibilidades que podem ser utilizadas para auxiliar e facilitar este processo, e agora de forma mais especial, em tempos de educação remota. Nossa pesquisa empírica apresentou como principais resultados os seguintes usos do uso deste artefato para avaliações no ensino superior: 1. Elaboração de atividades online de forma individual ou em parcerias; 2. Variadas possibilidades de questões; 3. Aplicação da avaliação presencialmente ou online; 4. Feedback instantâneo; 5 . Análise das respostas através de planilhas ou gráficos gerados automaticamente; 6 . Facilidade em realizar o download ou arquivamento no drive, bem como a possibilidade de acessá-lo de qualquer dispositivo conectado à Internet; e 7. Possibilidade de discussão dos resultados com os estudantes através dos relatórios disponiveis.

Desse modo, compreendemos a importância de saber lidar em aplicativos como - Google Forms, por parte de docentes que desejam realizar avaliações por competências aproveitando os beneficios das tecnologias digitais. Salientamos que este aplicativo pode dar suporte ao docente em seu diálogo com os estudantes a fim de esclarecer dúvidas e buscar desenvolvê-los constantemente em um ciclo de avaliação, feedback e ensino. Vemos, a partir de nossa pesquisa empirica, apoiada pelo referencial teórico, que ○ Google Forms possui funcionalidades que podem auxiliar o docente nas quatro etapas da avaliação por competências: elaboração da avaliação, aplicação da avaliação, análise dos resultados, e Feedback.

Em nossa análise dos achados empiricos surgiu a questão: 0 não uso de artefatos tecnológicos na avaliação do ensino superior se dá pela falta de formação, interesse ou resistência docente?. Em torno deste questionamento, consideramos que todas as três opções podem ser motivo para a não utilização de tecnologias para avaliações e merecem futuros estudos. É importante que os educadores tenham contato com esses artefatos desde sua formação inicial e, também sejam instigados ao uso de diferentes tecnologias em sala de aula para que se sintam-se motivados, evitando o desinteresse e a resistência.

Neste sentido, destacamos a importância tanto pessoal do docente em buscar conhecer e se apropriar das tecnologias para uso na educação, quando institucional e governamental, em propor uma formação inicial e continuada desses educadores para seu constante desenvolvimento. Além disso, indicamos como forma de possibilitar tanto - conhecimento, quanto o interesse e a diminuição de resistência pelas mudanças, a instauração de uma politica institucional para formação digital de seu pessoal docente e técnico-administrativo. 
Entre os principais avanços de nosso estudo destacamos nossa compreensão sobre a importância de uma formação docente voltada para as tecnologias, bem como uma política institucional que incentive e proponha ações neste sentido. Porém, indicamos como limitações deste estudo o fato de ele ter sido realizado no período anterior à pandemia de 2020 e da necessária virtualização das aulas, o que fez com que a totalidade dos docentes tivesse que recorrer às tecnologias digitais para a realização dos encontros síncronos, bem como para a realização das avaliações. Nesse sentido, indicamos para futuras pesquisas, a busca por dados que possam complementar este trabalho com a realidade pós-pandemia, a qual ainda nos traz muitas incertezas.

\section{REFERÊNCIAS}

ALMEIDA, M. C. S. P. Práxis docente: desafios e possibilidades para uma formação multicentrada na aprendizagem. 2018. Trabalho de conclusão de curso (Graduação em Educação Jesuítica) - Universidade do Vale do Rio dos Sinos, São Leopoldo, 2018.

BARDIN, L. Análise de conteúdo. São Paulo: Edições 70, 2011.

COLL, C. Las competencias en la educación escolar: algo más que una moda y mucho menos que un remedio. Aula de innovación educativa, v. 161, p. 34-39, 2007.

CRIAR fabulosos formulários. Google. Disponivel em: https://www.google.com/int//pt_br/forms/ about/. Acesso em: 8 out. 2018.

FAVARIN, E. do A.; DA ROCHA, A. M. Gestão educacional inovadora: o professor na cultura digital. Regae-Revista de Gestão e Avaliação Educacional, v. 4, n. 8, p. 59-78, 2015. Disponível em: https://www. redalyc.org/pdf/4718/471847065007.pdf. Acesso em: 25 mai. 2020.

FERREIRA, S. C.; MARASCHIN, C. Formação Docente, Políticas Cognitivas e Tecnologias Digitais. In: DIANA, J. B. Desenvolvendo e Agregando Valores na Educação a Distância. Ponta Grossa: Athena Editora, 2019. p. 14-25. Disponivel em: shorturl.at/msvD9. Acesso em: 5 jan. 2020.

FLEURY, M. T. L.; FLEURY, A. Construindo o conceito de competência. Revista de administração contemporânea, v. 5, p. 183-196, 2001. Edição Especial. Disponível em: shorturl.at/ouvy7. Acesso em: 5 jan. 2020.

GIL, A. C. Métodos e técnicas de pesquisa social. São Paulo: Atlas, 2008

GOERGEN, P. Educação \& Sociedade e as políticas públicas em educação. Educação \& Sociedade, v. 40, n. 1, p. 1-26, 2019.

GOMES, M. A. de 0. 0 Programa Mais Educação: uma proposta burguesa de educação integral. EDUCA-Revista Multidisciplinar em Educação, v. 5, n. 10, p. 131-148, 2018. Disponível em: shorturl.at/klqzK. Acesso em: 25 maio 2020. 
HABOWSKI, A. C.; CONTE, E.; TREVISAN, A. L. Por uma cultura reconstrutiva dos sentidos das tecnologias na educação. Educação \& Sociedade, v. 40, n. 4, p. 1-18, 2019. Disponível em: shorturl.at/jnwC8. Acesso em: 25 jun. 2020.

HOFFMANN, J. M. L. Avaliação mediadora: uma relação dialógica na construção do conhecimento. São Paulo: FDE, 1994.

KLEIN, T. R. M.; SCARPATTO, S. Avaliação escolar na educação básica. Maiêutica-Estudos Linguísticos, Literários e Formação Docente, v. 5, n. 1, 2017.

LAKATOS, E. M.; MARCONI, M. de A. Metodologia do trabalho científico: procedimentos básicos, pesquisa bibliográfica, projeto e relatório, publicações e trabalhos científicos. São Paulo: Atlas, 2001.

LEFRANÇOIS, G. R. Teorias da aprendizagem. 5. ed. São Paulo: GENGAGE Learninng, 2008.

LIBÂNEO, J. C. Didática. São Paulo: Editora Cortez, 2013.

LUCKESI, C. C. 0 que é mesmo o ato de avaliar a aprendizagem. Revista Pátio, v. 12, p. 6-11, 2000. Disponivel em: http://www.nescon.medicina.ufmg.br/biblioteca/imagem/2511.pdf. Acesso em: 16 jan. 2020.

MARINHO-ARAUJO, C. M.; RABELO, M. L. Avaliação educacional: a abordagem por competências. Avaliação: Revista da Avaliação da Educação Superior, v. 20, n. 2, p. 443-466, 2015. Disponivel em: shorturl. at/CIOQ1. Acesso em: 15 mar. 2020.

MARTINS, O. B.; MASCHIO, E. C. F. As tecnologias digitais na escola e a formação docente: representações, apropriações e práticas. Actualidades Investigativas en Educación, v. 14, n. 3, p. 479-301, 2014.

MOGNON, M. Google libera recursos de educação para ajudar professores e alunos durante a pandemia. Mundo Conectado, 2020. Disponivel em: https://mundoconectado.com.br/noticias/v/13106/ google-libera-recursos-de-educao-para-ajudar-professores-e-alunos-durante-a-pandemia. Acesso em: 30 jun. 2020.

PAUL, P. de L. Comparação crítica dos aplicativos Microsoft Excel e Google formulários, na execução de uma pesquisa com alunos de curso técnico. 2016. Trabalho de Conclusão de Curso (Especialização em Educação na Cultura Digital) - Universidade Federal de Santa Catarina, Florianópolis, 2016. Disponivel em: https://repositorio.ufsc.br/handle/123456789/168802. Acesso em: 10 fev. 2020.

QUADROS DA SILVA, L. de; FOSSATTI, P.; JUNG, H. S. Metodologias ativas: a Google For Education como ferramenta disruptiva para o ensino e aprendizagem. Revista Paidéi@-Revista Cient́fica de Educação a Distância, v. 10, n. 18, 2018. Disponível em: https://periodicos.unimesvirtual.com.br/index.php/paideia/ article/view/880. Acesso em: 12 fev. 2020. 
QUADROS DA SILVA, L. de. Novas metodologias na gestão acadêmica universitária: um estudo de caso na Unilasalle Canoas. 2019. Dissertação (Mestrado em Educação) - Universidade La Salle, Canoas, 2019. Disponivel em: http://repositorio.unilasalle.edu.br/bitstream/11690/1192/3/lqsilva.pdf. Acesso em: 5 jan. 2020.

REACT. Transformação digital no ensino: 5 tutoriais com ferramentas gratuitas para acelerar sua IE na pandemia. [S. l.: s. n.], 2020. Disponivel em: https://react.ag/transformacao-digital-no-ensino/. Acesso em: 12 mar. 2020.

ROCHA, J. D. T.; NOGUEIRA, C. da R. M. Formação docente: uso das tecnologias como ferramentas de interatividade no processo de ensino. Revista Observatório, v. 5, n. 6, p. 578-596, 2019. Disponível em: shorturl.at/aiALR. Acesso em: 12 fev. 2020.

SANTOS, V. S. dos. Como criar provas utilizando o Google Forms. Brasil Escola, [202-]. Disponível em: https://educador.brasilescola.uol.com.br/trabalho-docente/como-criar-provas-utilizando-o-google-forms.htm. Acesso em: 12 fev. 2020.

SILVA, K. N. P.; RAMOS, M. 0 ensino médio integrado no contexto da avaliação por resultados. Educação \& Sociedade, v. 39, n. 144, p. 567-583, 2018. Disponivel em: https://www.scielo.br/pdf/es/ v39n144/1678-4626-es-es0101-73302018186794.pdf. Acesso em: 3 fev. 2020.

VEGRO, T. C. et al. Cultura organizacional de um hospital privado. Revista Gaúcha de Enfermagem, v. 37 , n. 2, 2016. Disponivel em: https://goo.gl/qFa5ny. Acesso em: 27 fev. 2020.

ZARIFIAN, P. Objectif compétence: mythe, construction ou realité. Paris: Liaisons, 1999.

ZEFERINO, A. M. B.; PASSERI, S. M. R. R. Avaliação da aprendizagem do estudante. Cadernos da ABEM, v. 3, n. 4, 2007.

Endereço para correspondência: Avenida Vitor Barreto, 2288, 92310-000, Canoas, Rio Grande do Sul, Brasil; louise.quadrosdasilva@gmail.com 